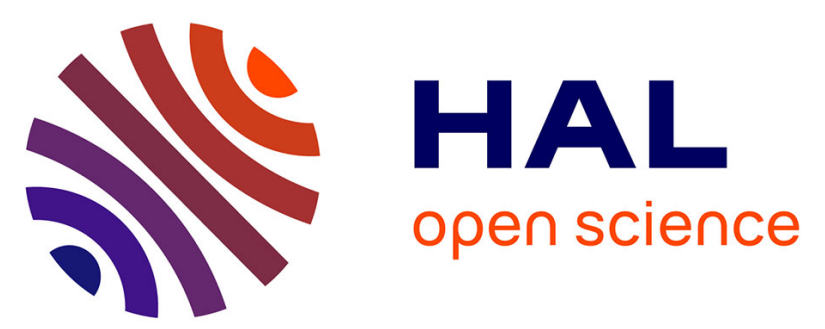

\title{
MeV, keV AND PHOTON INDUCED DESORPTION TIME OF FLIGHT MASS SPECTROMETRY
}

\author{
S. Della-Negra, J. Depauw, H. Joret, Y. Le Beyec
}

\section{To cite this version:}

S. Della-Negra, J. Depauw, H. Joret, Y. Le Beyec. MeV, keV AND PHOTON INDUCED DESORPTION TIME OF FLIGHT MASS SPECTROMETRY. International Workshop on $\mathrm{MeV}$ and $\mathrm{KeV}$ Ions and Cluster Interactions with Surfaces and Materials 2, 1988, Orsay, France. pp.C2-63-C2-68, 10.1051/jphyscol:1989212 . jpa-00229409

\section{HAL Id: jpa-00229409 https://hal.science/jpa-00229409}

Submitted on 1 Jan 1989

HAL is a multi-disciplinary open access archive for the deposit and dissemination of scientific research documents, whether they are published or not. The documents may come from teaching and research institutions in France or abroad, or from public or private research centers.
L'archive ouverte pluridisciplinaire HAL, est destinée au dépôt et à la diffusion de documents scientifiques de niveau recherche, publiés ou non, émanant des établissements d'enseignement et de recherche français ou étrangers, des laboratoires publics ou privés. 
JOURNAL DE PHYSIQUE

Colloque $C 2$, supplément au $n^{\circ} 2$, Tome 50, février 1989

\section{MeV, keV AND PHOTON INDUCED DESORPTION TIME OF FLIGHT MASS SPECTROMETRY}

S. DELLA-NEGRA, J. DEPAUW, H. JORET and Y. LE BEYEC

Institut de Physique Nucléaire, B.P. $n^{\circ} 1, F-91406$ orsay Cedex, France

Résumé: Un spectrometre de masse par temps de vol a eté utilisé afin de comparer les processus de desorption d'ions secondaires induits par des ions de quelques MeV, $\mathrm{keV}$ et par photons d'un laser pulse $\mathrm{N}_{2}$. Ies mesures sont faites avec les mêmes cibles (organiques et inorganiques) dans des conditions experimentales identiques quelle que soit la sonde de desorption (keV, MeV, laser). Le but de cette experience est de mesurer les rendements absolus d'émission secondaire et d'observer les differents modes de fragmentation suivant la sonde utilisée. L'utilisation d'un spectrometre de masse par temps de vol combiné avec diverses sondes de désorption-ionisation, peut conduire à une meilleure compréhension des mécanismes de désorption.

Abstract : An experimental comparison is presented concerning secondary ion desorption from insulators by $\mathrm{keV}$ and $\mathrm{MeV}$ heavy ion and by pulsed laser light. Time of flight mass spectra obtained with these desorption probes turned out to show many similarities $/ 1,2,3 /$ despite of the quite different energizing processes. Some corresponding data have been published already $11,2,3,4 /$. The aim of the present work is to measure absolute ion yields and to exhibit the virtually existing differences associated with the three desorption probes. This has an practical aspect, since the combination of the methods could inlarge their capabilities for mass spectrometry but it might also lead to a deeper understanding of the desorption mechanisms. The measurements were made with the same targets under the same experimental conditions whatever the desorption probes (keV, MeV, Laser).

\section{Experimental}

A multifunction reaction chamber has been built at the Institut for desorption mechanism studies 15\%. In this chamber the targets can be automaticaliy replaced. They can be moved to an intermediate position for cleaned (if necessary) by Ar ion etching or to the center of the chamber where irradiation by the following projectiles or laser light is possible :

- MeV ions from an accelerator

- keV ions from an ion source (ECR source for example/6/ or pulsed ion gun $17 / 3$

- Fission fragments from a retractable ${ }^{252}$ Cf source

- Lasers. 
The angle of incidence can also be changed since the time of flight mass spectrometer and the target are mounted on a platform which can be externally rotated. The absolute secondary ion yield of a given mass is defined as the number of detected secondary ions (corrected for the detection efficiency) divided by the number of primary ions bombarding the sample.

In this work we have used $\mathrm{MeV}$ ions from a ${ }^{252} \mathrm{Cf}$ source, keV ions from a pulsed ion gun instalied in the reaction chamber and a small pulsed UV laser. For these three probes the single ion counting technique has been used for time of flight measurements.

It is relatively easy to measure the exact number of fission fragments hitting a sample. It is less obvious to determine this number for $\mathrm{keV}$ ions impinging on a surface when the number of hits is small. The pulsed Cs ion gun has been built at the Institut. The intensity of the ion source is precisely controlled and a special procedure has been developed to measure accurately the number of primary ions hitting the target per pulse. For this purpose, a set of channel plates was placed just behind the target holder. With a target holder in position but no target, the pulsed beam passes through a hole in the holder. The time of flight of the primary ions can thus be measured between the instant the ions passing through the deflection plates in the gun and the instant they reach the detector. The number of $\mathrm{Cs}^{+}$time of flight events $n$ in this primary ion TOF spectrum is compared to the number of pulses $N$, in order to obtain the relative number of ions per pulse $N_{p}=n / N$ (this measurement is valid if $N_{p}$ ( 1$)$. The absolute value of ions per pulse $N p a$ is obtained by the expression $\mathrm{N}_{\mathrm{pa}}=0.6 \mathrm{x}$ P. $\mathrm{P}$ includes a Poisson correcting factor $\mathrm{P}=$ - $\mathrm{log}$ $(1-\mathrm{Np})$ and 0.6 is the channel plate detection efficiency factor.

Practically, in order to be sure to have either only one primary ion or none hitting the target, the average number of detected $\mathrm{Cs}^{+}$ions per pulse Np must be less than 0.2 primary ion per pulse. The beam current from the ion source is very stable $(v \pm 3 \%)$. Therefore, the monitoring of the number of ions per pulse was made for each target before and after the time of fight measurements.

In the negative mode (negative ions observed, target at a negative potential) the number of ions/pulse can be controlled during the experiment by counting the number of time of flight events in the T.O.F. electron peak.

The UV laser which has been used is a small power laser (given for 100 $\mu j)$. The width of the pulse at half maximum is $3 \mathrm{nsec}$, with a repeating rate of $20 \mathrm{~Hz}$. The power density at the sample was not measured precisely. It is estimated to be around $10^{5}$ watt $/ \mathrm{cm}^{2}$.

The sample material, deposited on an aluminized mylar foil was sometimes slightly marked after many seconds of laser shots but the target was not 
destroyed. The start signals for the secondary ion time of flight was obtained from a silicon detector triggered by the light scattered inside the chamber.

The same target was first bombarded by the fission fragments (from the backside of the target) then by the $\mathrm{Cs}^{+}$ions and finally by the laser light, most of the time in the positive or negative mode. Within a few minutes ToF spectra were recorded with the three probes. In principle a series of various targets could be investigated rapidly.

The ion desorption yield with laser shots has obviously not the same meaning as with $\mathrm{keV}$ and $\mathrm{MeV}$ ions because a large number of photons are interacting simultaneously with the sample material. However, it can be interesting to give the "apparent yield" which is the number of detected secondary ions (corrected again by the detection efficiency) divided by the number of shots).

Fig. I shows three spectra obtained with the $\mathrm{Cs}^{+}$gun, ${ }^{252} \mathrm{Cf}$ and UV laser and with the same coronene target $\left(\mathrm{C}_{24} \mathrm{H}_{12}\right)$. The molecular ion $300^{+}$is observed

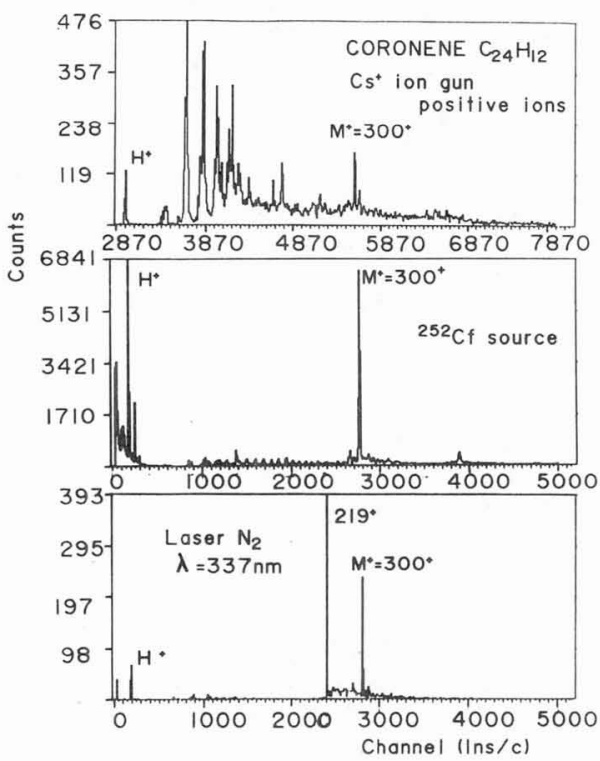

Fig. I : Positive ion time of flight spectra measured with the same target of coronene

$(M W=300)$ and the three desorption probes $\left(\mathrm{Cs}^{+}\right.$ion gun, fission fragments. $\mathrm{N}_{2}$ laser).

in all three spectra. A larger background is obtained with the $\mathrm{Cs}^{+}$ion gun because the desorption yield is small for this compound with keV ions (0.008\%) while it is around $30 \%$ with fission fragments. The moleculax peak is also clearly seen on the laser spectrum recorded with laser shots. The peak at $219^{+}$ is not explained but it is also seen with an Al-mylar target without any sample material on it.

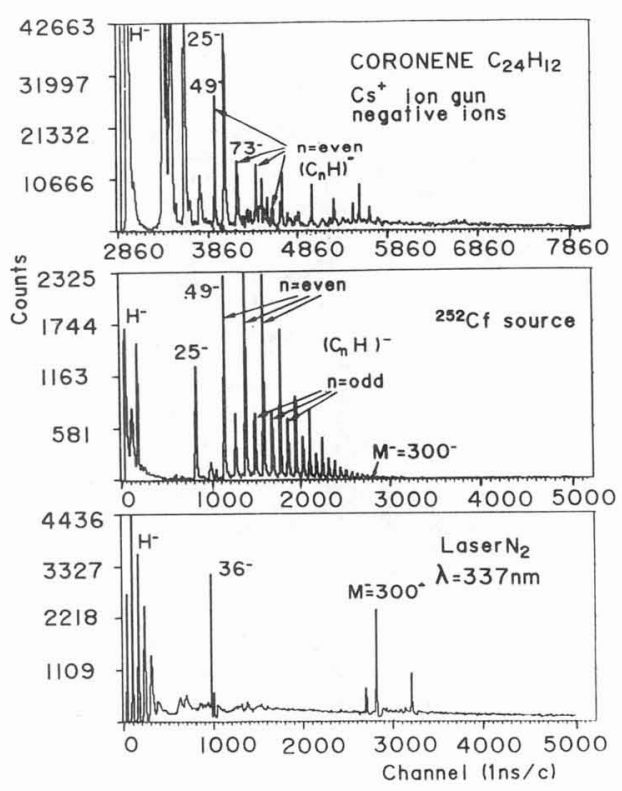

Fig. 2 : Negative ion spectra with the same coronen target as in Fig. 1 . 
Fig. 2 shows the negative spectra measured with the same target. Surprisingly, the negative molecular ion $300^{-}$is seen only in the laser spectrum. The ${ }^{252} \mathrm{Cf}$ spectrum exhibits a serie of $\left(\mathrm{C}_{n} \mathrm{H}^{-}\right.$peaks with a large abundance of the "even $n$ " peaks until mass 300. $\left(\mathrm{C}_{n} \mathrm{H}\right)^{-}$peaks are also observed in the keV spectrum but the odd-even effects are not as visible.

It is necessary to emphasize that complementary information is obtained with three different probes.

Other targets like CsI, crystal violet, Phenylalanine, Leu enkephaline, LHRH, Langmuir Blodgett films of $\mathrm{Cd}$ stearate have been compared.

Similar spectra of a crystal violet target were obtained with ${ }^{252} \mathrm{Cf}$ and $\mathrm{N}_{2}$ laser as shown in Fig. 3.

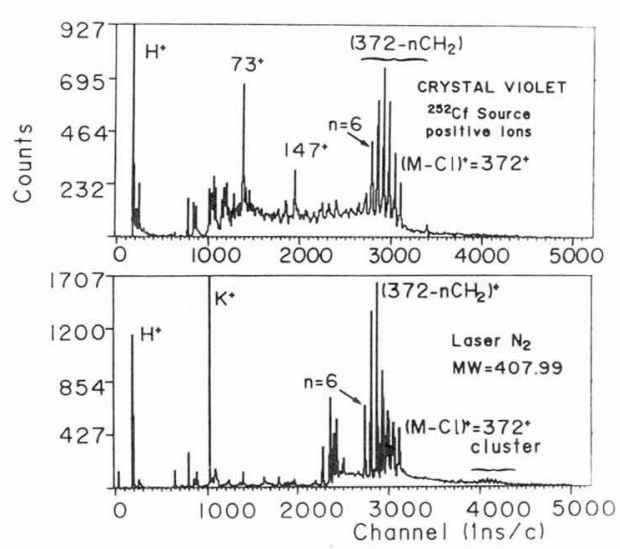

Fig. 3 : Positive ion spectra of the sample crystal violet, measured with fission fragments and $\mathrm{N}_{2}$ laser.

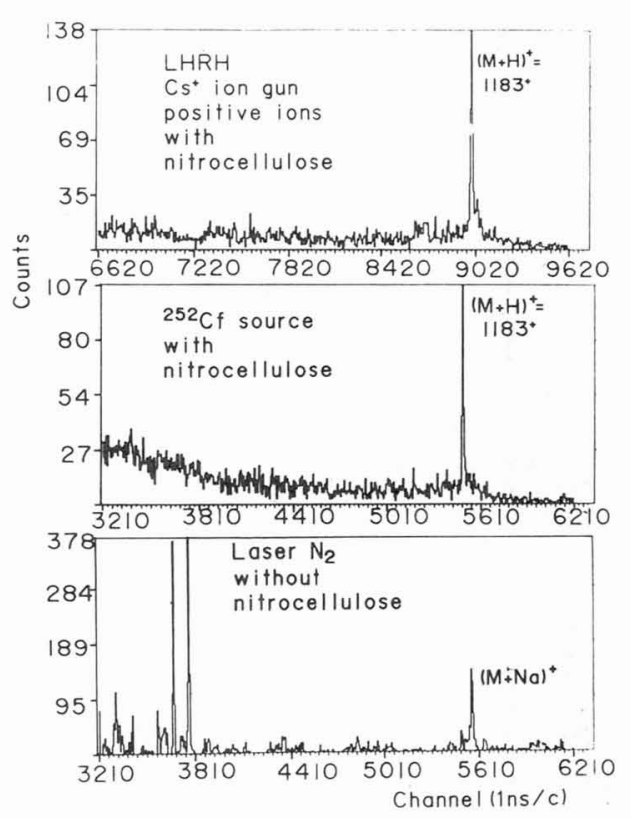

Ei_l : Positive ion spectra measured with an organic molecule : targets of LHRH ( $M W=1182$ ) bombarded by $\mathrm{Cs}^{7}$ ions, fission fragments and $\mathrm{N}_{2}$ laser.

With an organic target like LHRH (MW $=1182$ ), $\mathrm{keV} \mathrm{Cs}{ }^{+}$ions and $\mathrm{MeV}$ ions gave similar spectra (Fig. 4). The target was prepared by adsorption on nitrocellulose. The same target was investigated with the $\mathrm{N}_{2}$ laser and no molecular ion was observed in the laser spectrum. An electrosprayed target was then bombarded with the pulse laser light and a spectrum (low part of Fig. 4) was measured showing the presence of the peak $(M+N a)^{+}$. It is assumed that the molecules observed on nitrocellulose are more weakly bonded than to other molecules in a solid phase. This does not seem to be an important factor for the laser desorption. The differences observed between laser and $\mathrm{MeV}$ ions indicate that the desorption mechanisms are obviously different. and that more investigations with various targets would be very useful. 
Fositive molecular ions from electrosprayed phenylalanine and from leu enkephaline targets have not been observed with the $\mathrm{N}_{2}$ lasex $(\lambda=337 \mathrm{~nm})$. This is probably due to the photon energy ionization threshold which is not reached with the $\mathrm{N}_{2}$ laser. The absorption wavelenght associated with ionization is for example $269 \mathrm{~nm}$ for the phenylalanine molecule. Table 1 summarizes the yield values measured for various targets. These values have been corrected for detection efficiency.

It is observed that $\mathrm{MeV}$ ions are more efficient than keV ions, by a factor ranging from 20 to 100 . For organic materials on nitrocellulose a series of comparisons between $\mathrm{keV}$ and $\mathrm{MeV}$ ions over a mass range until 14000 was made by $W$. Ens et al /1/. A smaller yield value was also observed for keV ions.

YIELD PER ION OR LASER PULSE $\left(<10^{6} \mathrm{Watt} / \mathrm{Cm}^{2}\right)$ IN PERCENT :

\begin{tabular}{|c|c|c|c|}
\hline Target & Kev & $M e v$ & Laser $N_{2}$ \\
\hline $\begin{array}{c}C E S I U M \\
\mathrm{Cs}^{+}\end{array}$ & $15 \pm 0.5$ & $220 \pm 20$ & $\gg 100$ \\
\hline $\begin{array}{c}P H E N Y L A L A N I N \bar{E} \\
\text { (Evaporated.target) } \\
\text { Pos : } 166^{+} \\
\ldots\left(\mathrm{M}-\mathrm{CO}_{2} \mathrm{H}\right)^{+} \\
\text {Neg : } 164^{-}\end{array}$ & $\begin{array}{l}0.66 \\
0.80 \\
1.10\end{array}$ & $\begin{array}{l}14.1 \\
29.9 \\
89.3\end{array}$ & $\begin{array}{c}\text { molecular } \\
\text { ion } \\
\text { not.observed. }\end{array}$ \\
\hline $\begin{array}{c}\text { CORONENE } \\
\text { Pos.ions } \\
\text { Neg.ions }\end{array}$ & $\begin{array}{c}8.10^{-3} \\
\text { no.desorption } \\
\text { of.coronene } \\
\end{array}$ & $\begin{array}{l}30.7 \\
0.9\end{array}$ & $\begin{array}{l}35.5 \\
94.8\end{array}$ \\
\hline $\begin{array}{c}\text { Langmuir. Blodgett. films } \\
\text { Cd.stearate } \\
\text { Neg.ions : }(M-H)^{-} \\
\text {2.monolayers : } \\
\text { 8.monolayers: } \\
\end{array}$ & $\begin{array}{c}0.20 \pm 0.03 \\
\leq 0.3\end{array}$ & $\begin{array}{c}4.0 \pm 0.2 \\
29 \pm 1 \\
\end{array}$ & \\
\hline $\begin{array}{c}\text { CRYSTAL.VIOLET } \\
(M-C l)^{+}\end{array}$ & & 2.8 & 20.1 \\
\hline $\begin{array}{c}\text { LEU.ENK EPFALINE } \\
\text { without.nitrocellulose : } \\
\text { Pos.ions : }(M+H)^{+} \\
\text {..........(M+Na) } \\
\\
\text { with.nitrocellulose : } \\
\text { Pos.ions : }(M+H)^{+} \\
\text {Neg.ions : }(M-H)^{-}\end{array}$ & $(6.4 \pm 0.3) \cdot 10^{-2}$ & $\begin{array}{l}6.7 \pm 0.3 \\
1.2 \pm 0.1\end{array}$ & $\begin{array}{l}\text { not.observed } \\
\text { not.observed }\end{array}$ \\
\hline $\begin{array}{c}\text { LHRH } \\
\text { Pos,ions : } \\
\text { without.nitrocellulose } \\
\text { with.nitrocellulose }\end{array}$ & $(M+H)^{+}=0.41$ & $\begin{array}{c}(M+N a)^{+}=0.65 \\
(M+H)^{+}=13.4\end{array}$ & $\begin{array}{c}6.5 \\
\text { not.observed }\end{array}$ \\
\hline
\end{tabular}

Table 1

However with a pulsed $\mathrm{keV}$ ion beam, the number of ions per pulse can be increased in order to compensate the small efficiency of each single ion.

These first results with three desorption probes investigating the same targets show that complementary information can be obtain. The rate of secondary ion production, their initial energy distribution, their stability can be studied in the same apparatus according to the probe which is used. 
The basic research in that field will help to define more precisely the analytical properties and the specificity of the new time of flight instrument SuperDEPIL built at the Institut with financial support of CNRS and ANVAR.

We thank the staff of the mechanical and electronic workshops and namely J.P. Baronick for his very efficient contribution.

/I/ ENS, W., HAKANSSON, P., SUNDQVIST, B.U.R., SIMS VI, Versailles (1987), ed. A. Benninghoven, A.Huber, H.Werner, John Willey Sons (1987) p. 623.

121 ENS, W., MAIN, D.E., STANDING, K.G., and CHAIT, B.T., Analytical Chemistry 60 ( 1988$) 1494$.

/3/ BOLBACH, G., DELLA-NEGRA, S., DEPRUN, C., LE BEYEC, Y., STANDING, K.G., Proc. of the A.S.M.S. Meeting, Denver (USA), (1987).

$14 /$ GUTHIER, W., BECKER, O., DELLA-NEGRA, S., KNIPPELBERG, W. , LE BEYEC, Y., WINKEST, U., WIEN, K., WIESS, P. and WERSTER, R., Int. J. Mass Spectrom. Ion Phys. 53 (1983) 185.

$15 /$ DELLA-NEGRA, S., LE BEYEC, Y., MONART, B., STANDING, K.G., WIEN, K., Fhys. Rev. Lett. 58 (1987) 17.

$16 /$ DELLA-NEGRA, S., DEPAUW, J., JORET, H., LE BEYEC, Y. and SCHWEIKERT, E.A., Phys. Rev. Lett. 60 (1988) 10.

$17 /$ DELLA-NEGRA, S., DEPAUW, J., LE BEYEC, X., SIMS VI, Versailles (1987), ed. A. Benninghoven, A.Huber, H.Werner, John Willey Sons (1987) p. 251. 